\title{
9. El pensamiento político de Hegel
}

Para analizar el pensamiento político de Hegel, voy a tomar como trasfondo las ideas que he desarrollado en dos escritos míos anteriores titulados Hegel y la filosofia del derecho y Crítica de Hegel a Kant, sobre todo en lo que concierne a la visión de conjunto del pensamiento hegeliano en el contexto de su sistema global. Retomaré algunas de las ideas ya expuestas en lo que respecta a la doctrina del derecho, y trataré de profundizar en sus aspectos más relevantes, para examinar con particular atención lo que considero el núcleo central de las críticas de las que ha sido objeto su pensamiento político. Esto me permitirá trazar un lazo de unión muy significativo entre la doctrina hegeliana del derecho y el pensamiento de Baruch Spinoza.

Pasemos entonces a examinar los tres momentos del llamado por Hegel espíritu objetivo, que se corresponden precisamente con los que desarrolla su texto titulado Lineas fundamentales de la filosofía del derecho o compendio

* El texto fue publicado en una primera versión en: Hoyos 2004, p.240, libro que recoge las conferencias sobre filosofía política dictadas en la Universidad Externado de Colombia en el año 2004. 
de derecho natural y ciencia del Estado (1821) ${ }^{1}$. Pero antes de ello, considero necesario dejar sentados algunos puntos fundamentales sobre el concepto central de libertad, que nos orienten en nuestra exposición.

\section{El concepto de libertad}

Sabemos que con el término "espíritu" Hegel se refiere al mundo de lo humano, en cuanto el ser humano, en virtud de su propia naturaleza, se trasciende para entenderse como presencia real de lo divino o del logos a través de sus manifestaciones supremas: el arte, la religión y la filosofía. Ahora bien, Hegel nos dice que "la esencia del espíritu es formalmente la libertad, la negatividad absoluta del concepto como identidad consigo" (Enc. § 382); en otras palabras, que la absoluta identidad del concepto de espíritu conlleva la diferencia frente a todo otro y en eso consiste lo que cabe llamar la formalidad de la libertad en cuanto diferente de su contenido, es decir, en eso consiste el concepto abstracto de libertad. Si lo humano se caracteriza por la conciencia, es decir, por la conciencia de la propia identidad consigo (autoconciencia), en esta misma se fundamenta la idea de libertad como 'distancia' de sí mismo frente a todo lo otro.

Esa libertad le corresponde entonces al ser humano por su carácter de absoluta reflexión, es decir, por el hecho de que su naturaleza de ser pensante le permite saber de su identidad como resultado de su misma distinción tanto con respecto a lo otro, como también con respecto a sí mismo. Esta fórmula, que puede resultarnos extraña, no pretende otra cosa que expresar la experiencia que todos hacemos en nuestra propia conciencia; porque cada quien sabe de sí mismo, es consciente de sí, porque se hace objeto de su propia reflexión, con lo cual se distingue de sí en el mismo acto por el cual sabe de su diferencia frente a todo lo demás. Podemos formularlo en los siguientes términos: si bien en cierto que sé de aquello que es diferente de mí y en ese

1 El título de la traducción al español es Principios de la filosofía del derecho o Derecho natural y ciencia política. 
saber de lo otro me sé diferente de eso otro, si reflexiono con atención puedo ver cómo es precisamente el saber de mí como diferente de lo otro lo que hace posible el saber de lo otro como diferente de mí. En otras palabras, si paso del conocimiento de lo otro al conocimiento de mí, sin embargo veo que es el conocimiento de mí como diferente de lo otro lo que hace posible ese conocimiento de lo otro como diferente de mí. En términos más simples: paso de la conciencia de objeto a la autoconciencia, pero veo que la autoconciencia es condición de posibilidad de la conciencia de objeto; es decir, la conciencia de objeto es condición de posibilidad para conocer la autoconciencia, pero la autoconciencia es condición de posibilidad para el ser de la conciencia. Como sucede con frecuencia, el ordo cognoscendi es aquí inverso al ordo essendi.

Precisamente, esta característica del espíritu de saberse y por ello mismo saberse distinto de todo lo demás, incluso de su misma determinación en cada caso, es lo que constituye la forma misma de su libertad. De ahí que Hegel continúe en el mismo $§ 382$ :

Con arreglo a esta determinación formal, el espíritu puede abstraer de todo lo externo y de su propia exterioridad, es decir, de su mismo estar-ahí; puede soportar la negación de su inmediatez individual, el dolor infinito; o sea, que puede mantenerse afirmativo en esa negatividad y ser idéntico para sí. Esa posibilidad es su universalidad abstracta que-está-siendo-parasí en él.

Al subrayar el puede, Hegel nos indica que la libertad no es algo que pertenezca sin más a nuestra naturaleza, sino que podemos llegar a ser libres si reflexionamos de manera adecuada. Por eso leemos en la Adición (Zusatz) al mismo parágrafo ${ }^{2}$ :

2 Las adiciones provienen de las notas tomadas por sus estudiantes y no han sido publicadas en la edición de Friedhelm Nicolin y Otto Pöggeler, ni en la traducción de Valls Plana. Se encuentran en la edición de Eva Moldenhauer y Karl Markus Michel. 
Ahora bien, en su inmediatez, el espíritu es libre únicamente en sí, según el concepto o según la posibilidad, todavía no según la efectividad; la libertad efectiva no es, por lo tanto, algo queestá-siendo [que se da] de manera inmediata en el espíritu, sino algo que-hay-que-producir mediante su actividad (Enc. $§ 383$ Zusatz).

A su vez, esa capacidad reflexiva no sólo nos diferencia de todo lo demás, sino también de lo que estamos siendo en cada momento. Y que esta capacidad de abstracción o de diferenciación con respecto a todo lo dado, incluso a nuestra propia singularidad circunstancial, implique un "dolor infinito", lo atribuye Hegel a que nuestra conciencia reflexiva nos lleva a negar nuestra "inmediatez individual", es decir, nos hace tomar conciencia de nuestro carácter universal. En otras palabras, la libertad nos lleva a tomar conciencia de que no podemos obrar en función de nuestros intereses personales, de nuestra conveniencia individual, porque somos en realidad seres universales.

Precisamente la filosofía del derecho se propone examinar cómo el espíritu, que por su naturaleza puede llegar a ser libre, se construye un mundo intersubjetivo a su imagen y semejanza, gracias al cual su libertad pueda pasar de la posibilidad a la realidad. Por lo tanto, el objetivo de todo el ámbito del derecho, que arranca con el derecho abstracto de propiedad, continúa con el mundo de los principios morales y llega hasta el sistema de las instituciones estatales (derecho, moralidad, eticidad), no es otro que hacer efectiva esa libertad, otorgarle un contenido a esa forma que constituye la esencia de lo humano.

Conviene, sin embargo, tener en cuenta que la reflexión hegeliana, tanto en la Enciclopedia como en la Filosofía del derecho ${ }^{3}$, no avanza en un sentido histórico o temporal sino conceptual, es decir, que el hecho de que el espíritu objetivo se analice a continuación del espíritu subjetivo no significa que este

3 Cabe recordar que la Filosofía del derecho desarrolla los parágrafos que corresponden en la Enciclopedia al "espíritu objetivo". 
último sea la consecuencia o el resultado histórico del anterior. No es, como suele considerarse, que los seres humanos configuren sociedades para defender su libertad, como han pensado los llamados "contractualistas". Hegel considera que las cosas son al revés: los seres humanos son sociales por su misma naturaleza de pensantes y, gracias a ello, su libertad puede llegar a ser efectiva, de modo que, no es la libertad la que condiciona la vida social, sino que la vida social es la que hace posible la libertad, al menos en el campo conceptual.

Estas tesis de raíz liberal Hegel nunca las abandonó, como muy bien lo ha mostrado Jacques D'Hondt en su biografía de Hegel. Es cierto que con el correr del tiempo les fue dando un contenido cada vez más preciso, y que, al apartarse de Kant gracias a la influencia tanto de Hölderlin como de Schelling $y$, a través de este último, gracias a las ideas de Spinoza, fue viendo la necesidad de llenar las formas vacías de la ética kantiana con los contenidos de la cultura y de las instituciones que conforman una sociedad moderna. Pero ello, lejos de llevarlo a renunciar a su ideal de libertad, no hizo sino profundizarlo, al buscar hacerlo más real y efectivo.

En su análisis del contexto y de la estructura de la filosofía hegeliana del derecho, Kenneth Westphal hace notar, con razón, que:

Dado que los seres humanos actúan de manera colectiva para promover su libertad, la primera cuestión de la moderna filosofía política no es, a los ojos de Hegel, qué instituciones $a$ priori cumplirían esas funciones [de salvaguardar la libertad], sino más bien cómo y en qué medida cumplen esas funciones las instituciones que existen (Beiser 1996, 256).

Más allá de la filosofía crítica kantiana, que se queda en la defensa de un concepto abstracto de libertad y por ello mismo no puede otorgarle contenido alguno a sus reflexiones morales, Hegel propone avanzar hacia el estudio de las condiciones bajo las cuales los sujetos hacen real esa libertad. Porque sólo así, como trataré de mostrarlo más adelante, cree él que puedan superarse las 
irreconciliables contradicciones a las que se ve abocada una reflexión exclusivamente moral.

Ahora bien, es importante subrayar que la idea misma de libertad debe ser examinada con cuidado, porque esconde serios peligros de los que nos había advertido Spinoza.

De ninguna idea —nos amonesta Hegel en la nota al § 482 de la Enciclopedia - se sabe de manera tan general que se trata de una idea indeterminada, con muchos significados y capaz de los mayores malentendidos, a los cuales se encuentra realmente sometida, como la idea de libertad, y ninguna otra idea circula con tanta inconsciencia. Siendo el espíritu libre el espíritu efectivamente real, resulta que los malentendidos acerca de él tienen consecuencias prácticas más terribles que cualquier otra cosa, una vez que los individuos y los pueblos han captado en su representación [lo que para Hegel equivale a captar de manera inadecuada] el concepto abstracto de libertad que está-siendo para sí, representación que tiene una fuerza invencible, precisamente porque ella es la esencia propia del espíritu, y por cierto incluso como realidad efectiva suya [en otras palabras, como espíritu objetivo].

Hegel está pensando, sin duda, en la Revolución francesa, cuyo concepto abstracto de libertad la condujo a la llamada "época del terror", porque un concepto adecuado de libertad debe ser concebido, si se cumplen las condiciones señaladas por Spinoza, no como una voluntad capaz de hacer lo que a bien tenga más allá o más acá de los dictados de la razón, sino precisamente como la capacidad de obedecer dichos dictados, de aceptar su necesidad. Por ello no es correcto, como lo señala muy bien Valls Plana, que Hegel (como tampoco Spinoza) haya sostenido que la libertad no sea otra cosa que la necesidad concebida, y ello por una simple razón formal, que para quien conoce el método resulta clara: la libertad sigue al concepto de necesidad en el orden de la deducción, lo cual significa que la libertad es, por una parte, la superación 
de la necesidad y por lo tanto distinta de ella, y, por otra, que en ella la necesidad encuentra su verdad. La verdadera necesidad no es otra cosa que el trazo racional que va dejando el sujeto al obrar siguiendo su propia razón. Y esta es la verdadera necesidad, porque es la necesidad interior y no aquella que se le impone desde fuera.

Oigamos a Valls Plana, cuyos análisis del pensamiento hegeliano se caracterizan por su sencillez y claridad, por lo que me permito ofrecer una larga cita:

Libertad no es necesidad conocida. Deseo destacar solamente dos puntos: sostengo primero, de manera negativa, que libertad no significa para Hegel, de ningún modo, lo que tantos liliputienses le hacen decir, pretendiendo inmovilizar al gigante con ridículos hilos, a saber, que la libertad no es más que necesidad comprendida. No es así, porque siendo la libertad "la verdad de la necesidad" (Enc. § 158), esa expresión, técnica en el hegelismo, significa que libertad es la categoría que sigue a necesidad en la secuencia de la deducción de las categorías. Las dos son, por tanto, otras y distintas recíprocamente, siendo la segunda (libertad) más elevada, más concreta y más precisa que la primera (necesidad). [...] En segundo lugar, sostengo que, entendiendo el concepto como lo libre, Hegel excluye de raíz toda concepción que ponga el conocimiento en un bolsillo y la acción en el otro. Cualquier separación de ambas dimensiones del espíritu, entendidas, por ejemplo, como facultades distintas, falsea su mutua inmanencia. El querer que no sea conceptual (o racional) es inane o malo. El conocimiento que no sea espontáneo o libre es, a lo sumo, una forma de conocimiento inferior o inadecuado (Valls 2003, pp. 60-61).

Tal vez convenga, para precisar lo anterior, señalar que la libertad puede ser concebida como la necesidad interiorizada, es decir, como la acción que resulta de someterse a los dictados de la razón. Pero esa interiorización de la necesidad significa igualmente, para Hegel, su superación, es decir, su 
negación como necesidad exterior para ser elevada a un nivel superior. La necesidad interior viene a ser así la negación dialéctica de la necesidad exterior, pero no por ello deja de ser necesidad, sino que adquiere un sentido nuevo.

Una vez hechas estas precisiones acerca del concepto de libertad, de clara raigambre spinocista, sobre las cuales gira toda la concepción hegeliana del derecho, voy a entrar a examinar los momentos que constituyen al espíritu objetivo o al mundo de lo humano en cuanto realizado en la interacción de las conciencias como sujetos libres, en otras palabras, en el ámbito de la intersubjetividad.

\section{El derecho abstracto}

Hegel comienza por analizar la propiedad como primera manifestación de la libertad humana. En esta esfera inicial, y por lo mismo inferior, es decir más abstracta, el ser humano aparece como persona, o sea, como agente capaz de hacer abstracción de todo, de tal manera que, desde esa misma abstracción, exige ser reconocido por sus semejantes. Aunque la Filosofia del derecho no hace mención expresa del proceso de reconocimiento tal como fue presentado en la Fenomenología en tanto que experiencia de la conciencia, es claro que su desarrollo supone este concepto. Sin embargo, aquí, en el seno de una sociedad que se constituye como tal, ese reconocimiento comienza por el hecho de tomar posesión de algo. Ese sólo gesto tiene un carácter humano, porque su intención no se reduce al acto animal de asegurar su sustento o el de sus crías, sino que en el ser humano la intención es muy otra, hacerse reconocer como quien está por encima de lo dado y por lo mismo puede disponer de él. Esta interpretación de la propiedad como un derecho fundamental, que se extiende no solamente a las cosas externas sino igualmente a su propio cuerpo, le sirve a Hegel para explicar por qué la esclavitud, lo mismo que la pobreza absoluta, constituyen situaciones que vulneran ese derecho fundamental. La pobreza somete a los seres humanos a sus necesidades naturales, rebajándolos al nivel de la animalidad. 
Los tres pasos que escalonan el derecho abstracto o derecho de propiedad, mediante los cuales la conciencia se objetiva, no hacen sino desarrollar el concepto de propiedad hasta llevarlo al concepto de lo moral. En primer lugar, la propiedad es la base para el mutuo reconocimiento entre personas, de modo que cada una respeta la propiedad ajena y exige igualmente respeto por la propia. Esto sirve, en segundo lugar, de base al concepto de contrato, por el cual no sólo se demuestra la propiedad, sino también cómo las personas están por encima de esa propiedad: los contratos son los medios por los cuales la propiedad puede cambiar de dueño en un intercambio recíproco de bienes.

Las relaciones de propiedad, finalmente, dan pie a conflictos entre las personas, conflictos que en su nivel más simple se muestran como desavenencias que provienen de la falta de claridad sobre las determinaciones de la propiedad y que tienen su origen en el carácter empírico de los objetos poseídos o de los instrumentos para asegurar su posesión; a estos conflictos los llama Hegel "injusticia civil o ingenua" (Principios §84). Cuando en estos conflictos interviene de manera activa la intención aviesa de alguna de las partes, nos encontramos con el "engaño" (§87), cuya manifestación más elevada, es decir, más grave y más compleja, viene a ser "la violencia y el crimen".

La violencia y el crimen son la manifestación clara de una contradicción flagrante entre la voluntad particular del agresor y la voluntad general que debería guiar la relación entre personas. Una y otra suscitan la venganza, y esta genera un círculo de violencia que sólo puede ser roto por la intervención de un tercero, el juez, que permita desplazar la contradicción del ámbito de las personas enfrentadas y restablecer así el orden mediante el castigo, que se dirige entonces, no contra el agresor sino contra la agresión. Hegel sostiene una interpretación retributiva del castigo: el derecho lesionado exige una reparación, y las consecuencias benéficas que puedan seguirse del castigo no juegan un papel en la justificación del mismo. Sin embargo, resulta difícil explicar todos los castigos sin atender a las consecuencias, sobre todo en aquellos casos en que no se haya vulnerado de manera directa el derecho de otra persona. 
Ahora bien, el paso del derecho abstracto a la moralidad lo explica Hegel por la insuficiencia del primero para cumplir con su propósito de regular las relaciones externas entre las personas libres. Para ello, se requiere la presencia de un tercero, del juez imparcial, así como de un nivel de educación moral que el solo derecho no está en condiciones de garantizar. En efecto, el cumplimiento de las leyes no puede lograrse únicamente mediante la coerción de la fuerza, ya que exige una reflexión del agente que lo convierte de persona en sujeto moral.

En realidad, el proceso debe ser leído de la siguiente manera: en el orden conceptual, que corresponde al orden del conocimiento, la idea general o abstracta del derecho viene a exigir, para su realización, un sujeto moral; pero en el orden de la realidad es el sujeto moral el que sirve de fundamento al orden jurídico. Corresponde al modo de pensar de Hegel que los conceptos vayan mostrando su insuficiencia y exijan nuevos conceptos más complejos para superar las contradicciones que surgen de esa insuficiencia, pero los conceptos más complejos son en realidad el fundamento de los más abstractos o simples. Por eso, si el concepto de persona jurídica exige, para su realización, el de sujeto moral (Principios $§ 105$ ), es porque este último es condición de posibilidad del primero.

\section{La moralidad}

Hemos pasado así del momento objetivo del derecho y la persona, al momento subjetivo de la moral y el sujeto moral. El análisis del sujeto moral tiene un doble propósito: (a) por una parte, examinar los derechos fundamentales que le corresponden como sujeto autónomo y, por otra, (b) mostrar que los principios morales, al contrario de lo que pensaban Kant y Fichte, no pueden fundamentarse a priori.

(a) Hegel considera que el sujeto moral o "voluntad subjetiva" busca ante todo salvaguardar su autonomía, es decir, su capacidad de darse sus propias leyes. Es lo que Kant examinó con particular profundidad y agudeza. En este 
orden de ideas, el sujeto moral sólo puede aceptar responsabilidad por aquello que él mismo ha considerado como bueno y lo ha asumido como tal; en cuanto a las consecuencias de sus actos, no sólo deberá responder por las que él mismo previó, sino igualmente por aquellas que, como resultado de una sana reflexión, debería haber previsto.

El peligro que asecha a la moral es el subjetivismo, que puede llegar hasta el extremo de defender la bondad de una acción con total independencia de su contenido: la convicción del sujeto sería razón suficiente para justificar sus actos, sin atender a ningún elemento externo. Es el peligro que Hegel atribuye al formalismo moral de Kant, y en el que caía según él, la doctrina de su contemporáneo Jacob Friedrich Fries: se termina justificando así cualquier acción propia, al refugiarse en la buena intención que la guiaba, sin atender a las consecuencias de la misma, y, por otro lado, se logra extender un manto de sospecha sobre toda acción ajena, al desconfiar de las intenciones que la pudieron haber motivado. Hipocresía y soberbia vendrían a ser los peligros de una visión moralista del comportamiento humano.

De ahí la peligrosidad que encierra una fórmula, por lo demás muy hermosa, como aquella con la cual inicia Kant su Fundamentación para una metafísica de las costumbres: "Nada hay en todo el mundo, e incluso en general fuera de él, que pueda ser tenido sin limitaciones como bueno, a no ser una buena voluntad" (Fundamentación BA 2). Fórmula a la cual cabria contraponer el adagio popular: "De buenas intenciones está empedrado el camino al infierno".

(b) El origen de esa insuficiencia se halla en la pretensión de fundamentar los principios morales a priori, es decir, a partir de la sola consideración de la razón, sin prestar atención a ningún elemento externo, es decir, empírico. Hegel considera necesario tener muy en cuenta que las acciones humanas se mueven por fines que operan como razones, y que esos fines no pueden ser sino determinados, esto es, referirse a contenidos concretos. Pretender que sólo obramos correctamente cuando nuestro único motivo es el puro respeto a la ley, significa que nos quedaríamos sin razones para obrar, porque 
tendríamos que prescindir de toda motivación proveniente de fines. En buena medida, Hegel retoma por su cuenta la crítica de Friedrich Schiller al moralismo kantiano, crítica que ha sido muy bien examinada por María del Rosario Acosta en su libro La tragedia como conjuro: el problema de lo sublime en Friedrich Schiller.

Esto conlleva un cuestionamiento del imperativo categórico como criterio último de toda acción moral. Lo que se debe evaluar previamente no es la corrección formal de la acción con respecto a un principio abstracto, sino el carácter normativo que puedan tener las determinaciones concretas dentro de las cuales se lleva a cabo. Por eso resulta inaceptable la pretensión kantiana de fundamentar por la sola conciencia el carácter moral de una norma sin tener en cuenta el contexto real de su aplicación. La conciencia es sin duda un elemento necesario para la evaluación de ese carácter moral, pero no es suficiente. Si no confrontamos nuestras convicciones con el contexto real de su existencia, y si nos rehusamos a justificarlas ante nuestros semejantes, corremos el peligro de confundir nuestras certezas subjetivas con la verdad y caer así presa del fanatismo. "La certeza subjetiva — comenta con mucha razón Westphal - no es garantía de corrección de los principios morales; sin embargo, es esencial razonar con principios morales correctos".

No puede negarse que durante su periodo de Jena, bajo la influencia de su amigo Schelling, Hegel mostró una gran desconfianza frente el moralismo kantiano, como puede verse en su escrito El sistema de la eticidad, que él no publicó; pero en la Filosofía del derecho esta desconfianza, si no desaparece, al menos se aminora de manera significativa. Basta comprender la estructura de su pensamiento para ver cómo los dos primeros momentos del espíritu objetivo, el derecho abstracto y la moralidad, sin bien insuficientes y complementarios, no por ello carecen de valor, más aún, resultan indispensables. Hegel no niega que haya que cumplir el deber por amor al deber mismo, pero rechaza que haya que hacerlo así de manera exclusiva: la exclusión de todo interés o inclinación como elemento que empañaría con su misma presencia nuestra pureza moral es una exageración, fruto de un pensamiento abstracto. 
En su estudio sobre la filosofía y los derechos del hombre, Bernard Bourgeois hace notar la distinción que establece Hegel entre los derechos infra-civicos, es decir, aquellos que le corresponden al ser humano como tal o derechos del hombre propiamente tales, y que son los tratados precisamente bajo los títulos de derecho abstracto y de moralidad, y los derechos cívicos, es decir, los que le corresponden en tanto que ciudadano de un Estado de derecho y pertenecen al ámbito de la eticidad; $\mathrm{y}$, finalmente, los derechos supra-civicos, es decir, aquellos que le corresponden al ser humano en cuanto participa de las manifestaciones del espíritu absoluto, es decir, del arte, la religión y la filosofía. Tendré ocasión de volver sobre estas diferencias para examinar sus relaciones.

Por el momento, baste señalar que si la moral, como uno de los frutos más preciados de la modernidad, exige no solamente que hagamos lo que es bueno, sino que lo hagamos sabiendo que lo es, resulta necesario examinar esa bondad dentro del contexto concreto de su realización; no es posible, por lo tanto, centrarse en el yo y pretender desde allí justificar los criterios de acción. Esto implicaría negarse a dar razones y sustraerse a la intersubjetividad, lo que equivaldría a caer en el mal, según la concepción luterana del mismo. Lutero, en efecto, defiende una moral de la intención según la cual el valor de una acción no depende de la acción misma sino de la intención de quien actúa, retomando así la doctrina expuesta por Abelardo en el siglo XII. Pero su visión moral se ve equilibrada por el carácter religioso de la misma, ya que el criterio de la acción no se reduce a la pura intención, sino que se sitúa en la relación del alma con respecto a Dios. Hegel busca, en realidad, efectuar un paso equivalente, a saber, desde la pura subjetividad de la moral, tal como la concibió Kant, pasar a la objetividad del contexto histórico y cultural de la sociedad dentro de la cual obramos. Este es el paso que nos conduce a la eticidad. 


\section{La eticidad}

Conviene tener muy en cuenta que, para el método dialéctico hegeliano, este tercer momento no es únicamente un paso adelante, un avance conceptual, sino que constituye en realidad la síntesis y el fundamento de los dos pasos anteriores. En otras palabras, lo que Hegel pretende mostrar con esa división tripartita es que la eticidad constituye la condición de posibilidad de los dos momentos anteriores: el derecho abstracto y la moralidad. La idea que subyace a esta manera de ver las cosas es que el orden social dentro del cual nos hallamos situados, y que hace posible tanto la estructura de un derecho abstracto como la moralidad de nuestros actos, es un orden social al que le corresponde una presunción de racionalidad. No olvidemos que para Hegel el Estado no se identifica con el gobierno sino que abarca toda la estructura social de lo que llamamos un Estado de derecho, es decir, desde las familias hasta las estructuras de gobierno, pasando por las organizaciones de la sociedad civil.

Con ello pretendo señalar que tal orden social, constituido por las costumbres y leyes existentes, ha sido el resultado de un proceso histórico en que la razón ha jugado un papel innegable; pero esto no significa, como lo han entendido algunos, que Hegel pretenda justificar a priori el orden establecido. Su intención es señalar que, si tanto el derecho como la moral se desarrollan necesariamente en el seno de ese orden dado, más aún, si ese orden dado es el que hace posibles tanto al uno como a la otra, tenemos entonces que comenzar por someternos a él mientras no tengamos razones válidas para no hacerlo.

A ello apuntan sus duras críticas al subjetivismo, que tanto escándalo han causado en algunos de sus comentaristas, porque ven en ellas una simple defensa del statu quo, cuando, si bien es cierto que conllevan una dura crítica a la insuficiencia del pensamiento liberal tal como este aparece en Kant y Fichte, la intención es subrayar el peligro que encierra una visión exclusivamente subjetiva como la que sustenta la moral. No solamente tenemos que atender a las normas y costumbres de la sociedad en la cual vivimos, ya que es frente a tales normas como nuestros actos adquieren contenido moral, 
sino que, en el caso en que consideremos que tales normas no deben ser cumplidas y deben ser cambiadas, el peso de la prueba recae sobre nosotros.

El propósito de las consideraciones éticas es criticar las doctrinas morales o políticas que consideran las normas de conducta o las leyes de una sociedad como constricciones a la libertad, y por lo tanto como impedimentos para el despliegue de la misma, ya sea que estas constricciones provengan externamente de las leyes, ya sea que provengan internamente de nuestras convicciones morales. Un poco a la manera de la famosa paloma de Kant, no debemos pensar que el aire contra el cual agitamos las alas para volar sea un impedimento que nos restringe sino un apoyo que nos sostiene. Una función semejante desempeñan las leyes y las costumbres de una sociedad.

El término "vida ética" (Sittlichkeit) — comenta Allen Woodha sido acuñado para describir un estado de la voluntad humana en el que razón y sentidos están en armonía. Según esto, la "vida ética" se refiere originalmente a una ética del carácter que enfatiza las disposiciones racionales y el juicio práctico en situaciones concretas, en contraste con una moral de normas, donde el énfasis se halla en derivar acciones particulares de reglas generales.

Una persona virtuosa será aquella que logre armonizar su naturaleza con su razón, de modo que, a la vez que hace lo que debe, hace también lo que desea, ya que tan poco virtuoso es obrar el bien sólo por seguir el propio gusto, como lo es hacerlo por el solo deber y a regañadientes. Mientras que una visión moral del comportamiento resiente las normas como coacciones, la visión ética, por el contrario, las comprende como la sustancia misma del sujeto en la cual se hallan incluidos el amor familiar, la satisfacción del éxito profesional y el orgullo del buen ciudadano, para referirnos en forma esquemática a los tres niveles de la estructura ética: familia, sociedad civil y Estado.

El $§ 149$ de los Principios de la filosofía del derecho nos lo dice de manera expresa, de modo que vale la pena trascribirlo completo: 
El deber vinculante sólo puede aparecer como restricción frente a la subjetividad indeterminada o libertad abstracta, y frente a las tendencias de la voluntad natural, o frente a la voluntad moral que determina su bien indeterminado desde su arbitrio. El individuo, empero, halla en el deber más bien su liberación, por una parte, de la dependencia en la que se encuentra en el mero impulso natural, así como de la opresión en la que se encuentra como particularidad subjetiva en las reflexiones morales acerca del deber y del ser capaz, y, por la otra, de la subjetividad indeterminada que no llega hasta el estar-ahí y la determinación objetiva del actuar, sino que permanece dentro de sí y como algo inefectivo. En el deber el individuo se libera hacia la libertad sustancial.

El texto es claro: las normas que rigen el comportamiento social, que para la conciencia moral aparecen como restricciones que la someten y le coartan su libre albedrío, son más bien, para una conciencia desarrollada hasta la eticidad, las condiciones de su liberación. Por una parte, la liberan de la esclavitud de sus apetitos naturales así como de la indecisión a que la conduce una reflexión moral centrada sobre sus propios ideales de conducta y sus limitadas capacidades para cumplirlos. Tal vez Hegel estaría pensando en la experiencia moral de un Lutero, angustiado ante sus ideales de pureza moral y su incapacidad para ser fiel a ellos pese a sus reiterados esfuerzos. Por otra, liberan a la conciencia de una visión estrechamente moral o, como dice Hegel, de la "subjetividad indeterminada que no llega hasta la existencia y la determinación objetiva del actuar", sino que permanece encerrada en sí misma y en su universalidad abstracta, sin llegar a la acción que es siempre real y concreta. Figura que nos recuerda la del "alma bella", analizada en la Fenomenología. No olvidemos que el mismo Kant confesaba la imposibilidad de ofrecer un ejemplo concreto de un acto realizado por el sólo respeto al deber.

Así pues, la concepción ética implica cumplir los deberes, no tanto para buscar la satisfacción de intereses particulares o por el mero cumplimiento de leyes de carácter universal, sino por la necesidad que tenemos de reconocimiento, 
de ser aceptados como ciudadanos de un Estado que nos ofrece las condiciones para el ejercicio de nuestra libertad. Es cierto que Hegel comenzó concibiendo la eticidad bajo la imagen idealizada del mundo griego, en el cual los intereses del individuo se identificaban de manera inmediata con los intereses de la ciudad en la cual vivía como ciudadano libre. Pero poco a poco se fue alejando de este ideal, sin renunciar nunca por completo a él, en la me dida en que fue comprendiendo que la historia avanza de manera inexorable y no es posible retornar al pasado. En la Filosofia del derecho su visión es, por decirlo así, más moderna: se trata de reconciliar las normas sociales con la reflexión moral en el seno de instituciones organizadas para la defensa de la libertad, es decir, en el marco de un Estado de derecho.

Hegel nunca creyó que un Estado concreto, ni siquiera el prusiano, pudiera ser un modelo real de su Estado de derecho. Su propósito era ofrecer criterios objetivos para juzgar los Estados reales, los cuales deberían cumplir con dos requisitos básicos. Por una parte, debían ser estructurados de modo que integraran de manera coherente los múltiples aspectos de la vida pública: lo político, lo económico, lo cultural, lo religioso, etc. Por la otra, esa estructura debía funcionar en beneficio de las libertades fundamentales de los individuos, cuya libertad es el valor supremo y fundamental. Por eso, con respecto a las responsabilidades del gobierno, Hegel se regía por el principio proclamado por Fichte: “¡No, Príncipe, tú no eres nuestro Dios! De Él esperamos la felicidad, de $t i$, la protección de nuestros derechos. ¡Tú no debes ser con nosotros bueno, sino justo!" (Citado por Bourgeois, p.58).

Allen Wood señala con razón que hoy nos resulta difícil comprender la tesis hegeliana según la cual el Estado es la "realización de la idea ética" (Principios \$257) o la "realidad de la libertad concreta" (§ 260), porque concebimos al Estado ya sea como guardián del orden (conservadores), ya como protector de los derechos individuales (liberales), ya como defensor de los intereses de la clase dominante (marxistas).

Lo que distingue a Hegel virtualmente de todos los demás teóricos sociales modernos — señala Wood - es su concepción de 
que el Estado es fundamentalmente una institución ética, por lo tanto fundamentada, no en la coerción, sino en la libertad (§ 257). Él ve la fuente de su fortaleza no en la fuerza, sino en la manera como su estructura social organiza los derechos, la libertad subjetiva y el bienestar de los individuos en un todo armonioso, cuya unidad racional hace posible la identidad de cada individuo como una persona libre, un sujeto moral y un ser humano plenamente realizado.

Aunque Hegel mostró siempre una gran desconfianza hacia el pensamiento utópico, desconfianza que fue creciendo con el tiempo, su concepción del Estado, sin embargo, no puede menos de ser considerada como utópica: resultado de un pensamiento especulativo, muy alejado en esto de su mentor Spinoza. En este sentido, su crítica al liberalismo guarda sin duda un grave peligro de ser malinterpretada, como pueden serlo todas las utopías: verla convertida en un instrumento de destrucción de la realidad posible, o en un argumento engañoso para defender situaciones injustificables. El siglo XX nos ha ofrecido numerosos ejemplos de ello.

\section{Críticas a la doctrina hegeliana}

Las críticas a la doctrina hegeliana del derecho suelen centrarse en la relación que existe entre moralidad y eticidad, en otras palabras, en el punto mismo de la crítica de Hegel a la moral kantiana y de su propuesta de superación de la misma. Ya hemos visto en qué consiste lo fundamental de esta propuesta de superación: se trata de confrontar a la conciencia moral con la realidad concreta de las normas de conducta de la sociedad dentro de la cual vive y actúa. Y confrontarla no propiamente como si tales normas fueran lo opuesto a sus ideales de autorrealización, sino, bien al contrario, como las condicio nes mismas de posibilidad de esa realización.

Como lo señala con claridad Charles Taylor en su estudio sobre la relación entre Hegel y la sociedad moderna, la intención de Hegel es superar el dilema 
ante el cual se halla colocada la conciencia del hombre moderno, es decir, entender su libertad como capacidad de total auto-creación, o entenderla como la capacidad de total auto-dependencia. Y Hegel busca superar ese dilema al optar de manera decidida por el primero de los miembros y rechazar decididamente el otro, porque ser libre significa ser capaz de crearse a sí mismo, pero a condición de que esa auto-creación en la que consiste la verdadera libertad no signifique depender exclusivamente de sí mismo. Al contrario, tal auto-creación sólo puede llevarse a cabo a partir de una radical entrega con respecto al contexto social de su realización.

Me voy a permitir presentar una larga cita de Charles Taylor, por considerar que aclara muy bien lo que he venido diciendo:

La filosofía de Hegel constituye un paso importante en el desarrollo de la noción moderna de libertad. Él ayudó a desarrollar una concepción de libertad como total auto-creación, que sin duda era atribuible en su filosofía únicamente al espíritu cósmico, pero que sólo necesitó ser transpuesta al hombre para impulsar la concepción de libertad como auto-dependencia hasta su dilema extremo. Ha jugado así un papel importante en la intensificación del conflicto acerca de la moderna noción de libertad. Porque la libertad absoluta ha logrado su impacto sin precedentes en la vida y en las aspiraciones políticas de nuestro tiempo a través de la obra de Marx y de sus sucesores, cuya deuda con Hegel no necesita ser subrayada. (...) Al mismo tiempo, Hegel ha sido uno de los más profundos críticos de esta noción de libertad como auto-dependencia. Él sacó a la luz su vacuidad y su potencial poder destructor con una agudeza y una previsión dignas de encomio. En forma paradójica, ayudó a llevar esta doctrina moderna hasta su expresión extrema, así como a mostrar el dilema en el cual nos envuelve (1979).

Sin embargo, una crítica radical, y a mi parecer injusta, como la llevada a cabo por Amalia Vallcárcel en su análisis de la ética hegeliana, ve las cosas 
con otros ojos. Su trabajo, interesante por muchos conceptos, adolece, sin embargo, de una grave falla: "ha sido dictado — nos lo señala su prologuista Javier Muguerza - por un cierto despecho, el despecho de alguien que se hubiera sentido estafado" (Vallcárcel,1988, p. 12). Tales "pasiones tristes", como lo había presagiado Spinoza, nos deforman de manera peligrosa nuestra visión de la realidad, porque la tesis central de Valcárcel es que la superación de la "mera moral" por la ética no es más que el artificio mediante el cual Hegel sacrificó sus ideales revolucionarios de juventud en aras de un vergonzoso conformismo. Veamos sus propias palabras:

\begin{abstract}
Si Hegel decidió traicionar su herencia ilustrada y los primeros objetivos de su juventud, si esa traición le reportó además éxito, si la consumó tan perfectamente que la transformó en un nuevo sistema en el que las justificaciones llegaron a brillar más que los pensamientos originalmente denostados, no por su nitidez deja de ser lo que es $(1988$, p. 428).
\end{abstract}

En medio de este juicio y otros semejantes, a todas luces desproporcionados, la autora apunta con agudeza, sin embargo, al verdadero origen conceptual del problema, aunque lo hace con la consabida desmesura que la lleva a desconocer su verdadero sentido: "Lo que en el pensamiento hegeliano está en el fondo de la cuestión, en lo que a la ética atañe, es un tratamiento aberrante de la necesidad, que vicia completamente su especulación" (1988, p.135). Se trata, en realidad, de la concepción spinocista de la determinación, que Vallcárcel atribuye a las malas influencias de Schelling durante los años que compartie- ron en Jena.

Es un hecho que el pensamiento de Spinoza juega un papel fundamental en el idealismo alemán, papel que ella no logra comprender en su real significación. El concepto spinocista de "determinación" significa que nada puede existir que no esté determinado, es decir, que nada puede existir sin que de

4 Me he permitido retocar un poco la redacción en beneficio de claridad, sin cambiarle el sentido al texto. 
ello se pueda ofrecer una razón o una causa, de ahí que la voluntad haya que pensarla, no como un libre albedrío capaz de la más completa indeterminación, sino como la capacidad del ser humano para liberarse de sus determinaciones externas y ser determinado por su propia razón.

Hegel equipara la moral kantiana con el examen necesario, más aún indispensable, del momento en el que la conciencia se aparta de toda exterioridad para recogerse en su propio seno y descubrir la libertad como posibilidad de autocreación. Pero este momento, que se contrapone a la exteriorización tal como se da en el ejercicio del derecho de propiedad sobre las cosas, no debe concebirse sino como tal, es decir, como un momento de la unidad real y superior que es el Estado de derecho. Este último, la eticidad, no significa superar la moral en el sentido de excluirla, sino de elevar los dos momentos previos, derecho abstracto y moralidad, a su unidad dialéctica. Una verdadera Aufhebung, en el sentido hegeliano.

Bernard Bourgeois nos ofrece una consideración al respecto que me parece de la mayor importancia, porque nos permite comprender mejor la intención hegeliana al distinguir y ordenar los tres momentos de su filosofía del derecho: derecho abstracto, moralidad y eticidad. Para ello nos indica la relación que existe entre esos tres momentos, que, como dijimos, se corresponden, los dos primeros al análisis de los derechos del hombre como tal o derechos infra-cívicos, y el tercero al de sus derechos cívicos. Después de señalar cómo el Estado hegeliano tiene como función el afirmar de manera absoluta el derecho de sus momentos abstractos, es decir, del derecho y de la moralidad, continúa:

Y así como el Estado afirma de manera absoluta los derechos infra-cívicos, así también afirma absolutamente los derechos supra-civicos del ciudadano, es decir, sus derechos en tanto que él es más que ciudadano, en tanto que participa, para realizarse, del espíritu absoluto, en el arte, la religión y la filosofía; más aún, el Estado racional sabe que él tiene en este espíritu su fundamento absoluto, que debe, por lo tanto, afirmarse en él 
con todo su carácter absoluto, sirviéndole así para afirmarse él mismo de manera absoluta en su relatividad (92).

Y Bourgeois trae a continuación una cita expresa de Hegel:

Lo más elevado que puede lograr el Estado es que en él el arte y la ciencia se desarrollen, alcancen una altura que corresponda al espíritu del pueblo. Este es el objetivo más elevado del Estado, objetivo que, sin embargo, él no debe tratar de producir como su obra; este objetivo debe realizarse a partir de sí mismo.

Para rematar luego con el siguiente comentario:

Profundo liberalismo no político, no estatal, del Estado hegeliano, que le otorga su fuerza a la plena realización, en el ciudadano, de todos los momentos del espíritu, en tanto que ellos no son su momento objetivo supremo, el momento de la ciudadanía; pero que entonces, por oposición, constituyen su humanidad multiforme (93).

El sentido de estas consideraciones es darnos a entender cómo Hegel tiene plena conciencia de que, si bien es cierto que el carácter de ser humano es condición necesaria para la existencia del ciudadano y sus derechos, también lo es - $-\mathrm{y}$ esto es de la mayor importancia —, que la condición de ciudadano de un Estado de derecho, es decir, de un Estado racional, es condición de posibilidad de la existencia real de esos derechos del hombre, tanto los básicos como los más elevados. Es en este preciso sentido en el que Hegel puede afirmar el carácter absoluto del Estado: porque sirve de fundamento y de condición de posibilidad para la realidad efectiva de los derechos humanos, más allá de la cual no cabe una posible apelación. Por eso puede Bourgeois terminar su reflexión con una frase que no podrá menos que ofender los piadosos oídos de cualquier liberal puritano: "El estado «totalitario», donde el ciudadano no es tal como él mismo se hace de manera individual sino porque 
asume su inserción originaria en la comunidad, es aquel Estado que trata lo más liberalmente al hombre en el ciudadano".

Ahora bien, si queremos preguntar dónde podrían hallarse entonces los elementos realmente discutibles y hasta inaceptables del punto de vista político de Hegel, creo que deberíamos irlos a buscar en otra dirección. Y considero que es Charles Taylor quien nos indica esa dirección correcta, y lo hace apuntando precisamente a la influencia que ha podido tener Spinoza sobre el pensamiento hegeliano. Voy a permitirme de nuevo una larga cita:

El creciente control de la moderna tecnología sobre la naturaleza, así como la continua expansión de las fronteras de la ciencia, han disipado esa visión del mundo como la manifestación de poderes espirituales o de un principio divino, que fue la culminación de la corriente expresivista de finales del siglo XVIII. Este panteísmo expresivo, el "spinocismo" del Sturm und Drang, que tentó a Lessing, casi conquistó a Herder y fue propiedad común de Goethe y de los Románticos, dejó de ser una opción viva cuando la civilización moderna se hizo fuerte. Ahora bien, la síntesis de Hegel estaba construida sobre esos cimientos. [...] Pero si esta visión de panteísmo expresivo se desvanece, si la aspiración a la unidad con el "todo de la naturaleza" [expresión de Hölderlin] deja de tener sentido, entonces desaparece la base misma de la Idea Absoluta, junto con los Urphänomene de Goethe, el "idealismo mágico" de Novalis y las más extrañas creaciones de los Románticos.

Podríamos entonces preguntarnos ¿qué etiqueta cabría ponerle a la teoría política hegeliana? ¿Cómo podríamos situarlo dentro del espectro político moderno? ¿Fue en realidad un defensor un tanto solapado del Estado prusiano? ¿O siguió siendo fiel a sus convicciones liberales, a pesar de sus duras críticas el liberalismo? Mientras Taylor considera que "la teoría política Hegel en realidad no tiene ni precedente y ni paralelo" (81), Westphal, en cambio, sostiene expresamente que "Hegel es un liberal reformista que apoyó su filosofía 
política en el análisis y la realización de la libertad humana individual”. Sin embargo, valdría la pena preguntarse cuál es en realidad el beneficio de tales etiquetas ¿no sería acaso mejor prescindir de ellas y concentrarnos en comprender el verdadero fondo de los problemas? 